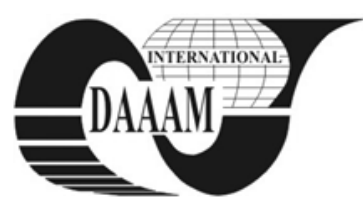

Annals of DAAAM for 2011 \& Proceedings of the 22nd International DAAAM Symposium, Volume 22, No. 1, ISSN 1726-9679 ISBN 978-3-901509-83-4, Editor B. Katalinic, Published by DAAAM International, Vienna, Austria, EU, 2011 Make Harmony between Technology and Nature, and Your Mind will Fly Free as a Bird Annals \& Proceedings of DAAAM International 2011

\title{
FABRIC REINFORCED LAMINAE AND LAMINATES WITH STARCH-EPOXY MATRIX
}

\author{
BRIA, V[asile]; CIRCIUMARU, A[drian]; BIRSAN, I[ulian] G[abriel]; ANDREI, G[abriel]; \\ DIMA, D[umitru] \& ROMAN, I[gor]
}

\begin{abstract}
Despite their mechanical properties, lower than the fibers ones, the fabrics are more and more used as reinforcements in composites applications due their capacity to allow draping in order to form materials and/or structures with sinuous surfaces. The present study is connected to the idea of forming multi-plies composites with the same matrix but with different types of fabrics as reinforcement in order to maximize more than one mechanical property by design means. Fabric reinforced laminae are tested in order to identify the optimal orientation of each type of fabric inside the material. Three types of fabric are used to form epoxy matrix laminae which are tensile tested. All the fabrics were specially prepared to ensure a better adhesion of epoxy resin.
\end{abstract}

Key words: starch, epoxy, fabrics, laminate model

\section{INTRODUCTION}

Generally the composites are formed just to maximize one of the material or structure's properties, for example the tensile strength. Other properties, required by the application, have to be solved by other meanings and means when the material or the structure is finalized. Thus, the design of material is taking into consideration just the property to be maximized even if some other properties are lowered. This study is about forming an epoxy based plate of layered composite trying to reach maximization not only for one property but for more than one. The main idea is to find a right placement of three types of fiber fabrics, used as reinforcements, in order to reach higher mechanical properties (tensile strength, shock resistance, compression resistance) together with some better physical properties (thermal conductivity, electrical conductivity).

As it is well known it is possible to design a composite plate when orthotropic laminae are used. The models used to describe the mechanical properties of the laminate in terms of individual ply's mechanical constants; orientation and depth in the material are strong enough to predict plate's mechanical properties (Daniel \& Ishai, 2006; Gay et al, 2003; Jones, 1998). But what about the case of a laminate like material in which each ply is realized from fabric? This study is meant to identify ways to characterize the fabric reinforced plies in order to determine their mechanical parameters to be used to design the laminate like materials (Long, 2005; Onate \& Kopling, 2005; Sanjay, 2002) or model by neural networks means (Radovanovic \& Madic, 2010).

By laminate like materials it is understood a reinforced composite with the same matrix in all its volume. In this case the individual plies are not stickled together but using a bicomponent epoxy system as matrix the polymerization takes place in the mean time in all the directions inside the material leading to polymer chains not between individual laminae but through them. In this case when the material is loaded the efforts are on the entire matrix and the transfer between matrix and reinforcement is realized through interface (not through an intermediary material as in the laminate's case). In this respect it is very important to ensure a high quality interface between polymer and textiles (fabrics).
Another interesting aspect is connected with the opportunity to fill the polymer with certain fillers and to obtain multi-phase composites solving this way not only the mechanical properties but also the electro-magnetic or thermal ones. More than that it is possible to realize a material with more than one type of fabric and more than one type of filler obtaining a complex structure with designed (at least, designable) properties to fit more requirements.

\section{MATERIALS}

Three types of fabric were taken into account due to their genuine properties. All of the fabrics consist of untwisted tows of fibers used as warp and weft such as all the fabrics are simple type (or plane) with each tow of weft passing alternately above and under consecutive warp tows. In the case of mixed fabric (realized from carbon fibers and aramide fibers tows) the arrangement of tows is different. The weft is realized from alternately two tows of aramide and one of carbon while yarn is with two tows of carbon and one of aramide. In Table 1 there are presented the dimensional characteristics of the three used fabrics.

\begin{tabular}{|l|l|l|l|l|}
\hline Fabric & Fiber & $\begin{array}{l}\text { Weft } \\
\text { Tow }\end{array}$ & $\begin{array}{l}\text { Warp } \\
\text { Tow }\end{array}$ & $\begin{array}{l}\text { Fabric } \\
\text { Thickness }\end{array}$ \\
\hline Glass & Glass & 1.35 & 1.35 & 0.23 \\
\hline Carbon & Carbon & 2.15 & 2.15 & 0.21 \\
\hline \multirow{2}{*}{ Mixed } & Aramide & 2.00 & 2.00 & \multirow{2}{*}{0.25} \\
\cline { 2 - 5 } & Carbon & 1.58 & 1.58 & \\
\hline
\end{tabular}

Tab. 1. Dimensional characteristics of fabrics [mm]

The mentioned fabrics were prepared to ensure matrix adhesion and stability during handling. The first step of the preparation consisted in washing with detergent solution and rinsing to clean the surface of the fabrics. The second step, chemical attack with Natrium hydroxide and Hypochlorite solutions to raise the specific area of fibers (and tows). After each stage of the chemical treatment the fabrics were washed and rinsed. The last step of the preparation consisted in deposition of a thin film of epoxy on the surface of the fabrics such as to ensure the fabrics stability without covering the empty spaces between weft and warp tows.

The EPOLAM 2015 - EPOLAM 2014 from Axson technologies epoxy system's components were diluted in nitro solvent and the solution was sprayed consecutively on the surface of the fabric. After the solvent vaporization the two components interacted and the polymerization left the epoxy thin film on the fabric.

The final materials (epoxy fabric reinforced plies) were formed between two glass sheets with controlled pressure such as the excess of pre-polymer poured outside the open mould. The matrix for the plies was realized from the named epoxy resin with an amount of $10 \%$ (volume ratio) of starch. The dispersion of starch was made into the pre-polymer mixture of epoxy system (20 minutes after the mixture of the two components was made). 

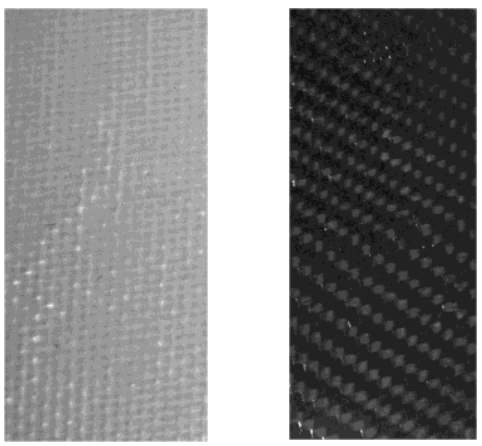

Fig. 1. Images of the three types of formed plies

Using the same prepared fabrics, stratified materials were formed having structure given in Table. 2. where $M$ denotes mixed fabric, $\mathrm{C}$ carbon fiber fabric and $\mathrm{G}$ glass fiber fabric.

When a layered material is formed its properties might be predicted knowing the mechanical parameters of each ply together with its orientation inside the stratified material (Pukanszky, 2007; Ben Boubaker et al., 2007; Karkkainen, et al., 2007).

\begin{tabular}{|c|c|}
\hline Material & Reinforcement structure \\
\hline R1 & $\mathrm{M} 0^{\circ}-\mathrm{C} 0^{\circ}-\mathrm{G} 0^{\circ}-\mathrm{G} 0^{\circ}-\mathrm{G} 0^{\circ}-\mathrm{C} 0^{\circ}-\mathrm{M} 0^{\circ}$ \\
\hline $\mathrm{R} 2$ & $\mathrm{M} 0^{\circ}-\mathrm{C} 0^{\circ}-\mathrm{G} 30^{\circ}-\mathrm{G} 0^{\circ}-\mathrm{G} 30^{\circ}-\mathrm{C} 0^{\circ}-\mathrm{M} 0^{\circ}$ \\
\hline R3 & $\mathrm{M} 0^{\circ}-\mathrm{C} 0^{\circ}-\mathrm{G} 45^{\circ}-\mathrm{G} 0^{\circ}-\mathrm{G} 45^{\circ}-\mathrm{C} 0^{\circ}-\mathrm{M} 0^{\circ}$ \\
\hline R4 & $\mathrm{M} 0^{\circ}-\mathrm{C} 15^{\circ}-\mathrm{G} 30^{\circ}-\mathrm{G} 0^{\circ}-\mathrm{G} 30^{\circ}-\mathrm{C} 15^{\circ}-\mathrm{M} 0^{\circ}$ \\
\hline R5 & $\mathrm{M} 0^{\circ}-\mathrm{C} 15^{\circ}-\mathrm{G} 45^{\circ}-\mathrm{G} 0^{\circ}-\mathrm{G} 45^{\circ}-\mathrm{C} 15^{\circ}-\mathrm{M} 0^{\circ}$ \\
\hline R6 & $\mathrm{M} 0^{\circ}-\mathrm{C} 30^{\circ}-\mathrm{G} 30^{\circ}-\mathrm{G} 0^{\circ}-\mathrm{G} 30^{\circ}-\mathrm{C} 30^{\circ}-\mathrm{M} 0^{\circ}$ \\
\hline
\end{tabular}

Tab. 2. Reinforcement structure of formed materials

\section{MEASUREMENTS AND RESULTS}

The Testometric 5K M350 machine was used to the materials under tensile loading and bending loading. In both the cases the loading speed was set at $0.5 \mathrm{~mm} / \mathrm{min}$ to allow a static distribution of loading.

Basically the aim of this study is to verify how the orientation of reinforcement sheets is influencing the final mechanical properties of epoxy matrix material taking into account the same sequence of reinforcement layers.

Placing the aramide fibers at external layer it is possible to protect the more fragile fibers of carbon and glass from inside layers. The carbon fiber fabric used at the next level and having contacts with the carbon fiber from external layers might improve the surface electric conductivity of formed materials while the glass fibers at the core of material might be necessary to ensure the compressive strength of the materials.

Samples from each material were extracted at $0^{\circ}$ and $90^{\circ}$ taking into account that mixed fabric is not balanced and it might determine some changes on stratified behavior.

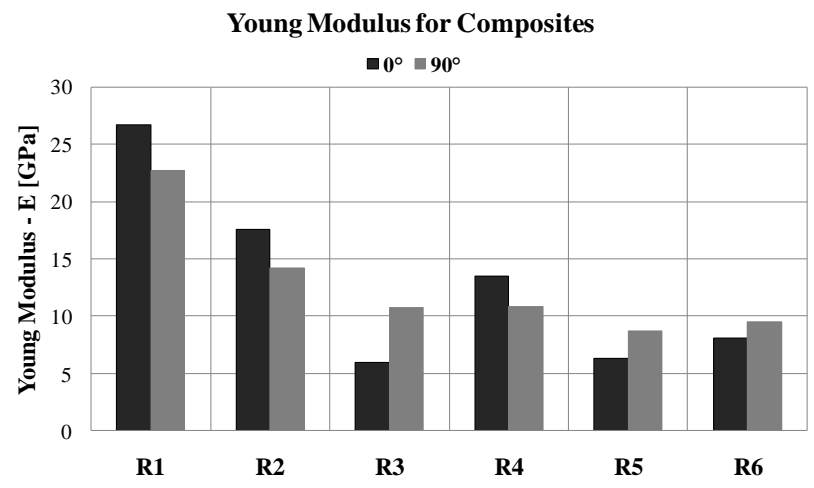

Fig. 2. Young modulus for stratified materials
As it may be noticed from Fig. 2 the Young modulus decreases when some of the layers are oriented at various angles. The worst situation is reached in the case of $\mathrm{R} 3$ and this behavior is explainable by glass fiber fabric laminae behavior and by the fact that there are discontinuities between layers due to the orientation and due to the fabrics self arrangement it is possible the direct contact between fibers in absence of resin. The highest value of Young modulus is reached at reference sample (R1) and is generated by the longitudinal loading of long fibers - in other cases some layers are consisting in a regulated distribution of short fibers and are generating a plastic behavior.

\section{CONCLUSIONS}

The results of this study might be used to verify the known mixing rules (for physical properties) and the laminate's engineering constants equations when the physical and mechanical properties of individual laminae are measured. In fact this would represent an empirical-theoretical model of laminates with fabric reinforced laminae.

Analysis must be performed in order to identify the optimal placement of the three types of fabric inside the material. Physical and tribological properties of formed materials have to be investigated to determine the influence of fabric layers sequence and fabric orientation effects. Aiming to control the final properties of a reinforced material by means of filling the matrix it is necessary to study the same materials' structures but with filled epoxy matrix.

In this case studies must be carried out to point out the critical concentration for each of different fillers (the maxim concentration for which polymer's mechanical response is not damaged). In this case and with the mentioned forming technique is possible to "place" a certain property inside the material almost without changing the mechanical parameters of the formed material. It is also possible to design the fabric in order to achieve a certain property. Anyway at the external layers it seems to be necessary to place mixed aramide and carbon fibers fabric to ensure the chock resistance (due to aramide fibers) and to control electrical conductivity (due to the carbon fiber). Such a structure will protect the inside glass fiber fabric.

\section{REFERENCES}

Ben Boubaker, B. et al. (2007), Discrete models of woven structures. Macroscopic approach, Composites: Part B, 38, pp. $498-505$

Daniel, I \& Ishai, O. (2006), Engineering Mechanics of Composite Materials, Oxford University Press, 019515097X, New York, USA

Gay, D. Et al (2003), Composite Materials - Design and Applications, CRC Press, 58716-084-6, Boca Raton, USA

Jones, R.M. (1998), Mechanics of Composite Materials, Taylor\&Francis Inc., 1-56032-712-X, Philadelphia, USA

Karkkainen, R. L. et al., (2007), Strength prediction of multilayer plain weave textile composites using the direct micromechanics method, Composites: Part B, 38, pp. 924932

Onate, E., Kroplin, B., (eds) (2005), Textile Composites and Inflatable Structures, Springer, ISBN-10 1-4020-3317-6 (ebook)

Pukanszky, B. (2007) Mineral-filled polymers, in Mortensen, A., Concise Encyclopedia of Composite Materials, Elsevier

Radovanovic, I, Madic, M. (2010), Methodology of Neural Network Based Modeling of Machining Processes, International Journal of Modern Manufacturing Technologies, pp. 77 - 82, ISSN 2067-3604, Vol. II, No. 2

Sanjay, K.M. (2002), Composites Manufacturing, CRC Press, 0-8493-0585-3, Boca Raton, USA 